\title{
La imagen alfonsina del Palacio Real de Madrid
}

\author{
JOSÉ LUIS SANCHO *
}

A finales del siglo xix el Palacio Real de Madrid sufrió una reforma que supuso un cambio importante en el aspecto interior de esta residencia real. En 1879 y con el segundo matrimonio de Alfonso XII como causa inmediata, la decoración se puso al servicio de una escenografía monárquica bastante diferente a la isabelina. Los cambios no fueron en absoluto puntuales, sino que respondieron a una campaña global y pensada de una vez, cuyas cabezas más destacadas fueron el arquitecto mayor de Palacio, José Segundo de Lema, y el conde de Valencia de Don Juan como asesor histórico-artístico, y que estaba en perfecto acuerdo con el momento político y el gusto de su momento. La restauración alfonsina, ya consolidada, exigía una imagen oficial de la monarquía en la cual el lujo inherente a la representación no podia quedar encerrado en perpetuar la pompa dieciochesca, según había señalado un publicista tan notable como Galdós.

Por otra parte, este deseo de crear un marco suntuario para la vida del monarca concordaba no sólo con la imagen oficial francesa, donde Napoleón III y la Tercera República habian acuñado un estilo enfático, sino además con el gusto en general de la burguesía conservadora, que asimilaba una gran cantidad de historicismos, desde los medievalismos al rococó, subordinándolos a la ostentación y al boato.

De este modo, en el Palacio de Madrid surgirá el salón de baile y comedor de gala, de estilo ecléctico muy acorde con el neobarroco francés de ese momento y donde se reaprovechan tapices del XVI fijándolos

Departamento de Arquitectura del Patrimonio Nacional. 
en los paramentos; junto a él, una habitación decorada con talla neoplateresca, acorde con otros elementos dispersos por el Palacio como muebles o esculturas copiados del siglo xvi; un salón de billar en una suerte de neogótico racionalista al modo de Viollet-le-Duc; una sala de fumar chinesca, o japonesa - de una manera y de otra la nombran los documentos- $y$, por último, el Palacio experimentó su primera restauración que merezca tal nombre y no el de simple reparación: el arreglo de la Cámara de Gasparini.

Por tanto, el tema resulta curioso desde dos puntos de vista: el histórico-sociológico o de imagen de la monarquía, y el puramente artístico. Por lo que a este último se refiere, hemos de destacar la dirección del arquitecto mayor de Palacio José Segundo de Lema. Bastante poco estudiado, Lema es conocido sobre todo por el Panteón de Infantes en El Escorial (proyecto de 1862) y también por una notable residencia privada que puede relacionarse con este trabajo suyo en Palacio tanto por su inspiración general violletleduquiana como por el hecho de haber trabajado en ello también como arquitecto de interiores: el Palacio de Zabálburu o de Heredia Spínola, en Madrid (1878).

La obra de Lema en Palacio, nunca mencionada siquiera, depende evidentemente de la práctica contemporánea inglesa y francesa, donde los salones neobarrocos turcos, chinos, etc., proliferaban para hacer variados los ostentosos interiores de la alta burguesía. Por tanto, todas estas decoraciones no son sino un reflejo, aunque digno, del extranjero, o por decirlo de otro modo el intento alfonsino de crear un interior victoriano para la Corte española. Por desgracia, la mayor parte de los interiores decimonónicos madrileños a la moda de París y Londres han perecido con los palacios que los albergaban en la Castellana, pero subsisten algunos como el de Salamanca, el de Parcent - cuyos salones principales no son copia sino importación, pues fueron diseñados en 1862 por el principal arquitecto decorador del momento, Galland-o el de Santoña, hoy sede de la Cámara de Comercio, por no citar otros -Fernán Núñez, Cerralbo, Linares- o los desaparecidos, como el de Medinaceli.

La comparación de estas residencias con los salones creados en Palacio por la Restauración permite comprender con mayor claridad lo que unía y lo que separaba a la representación palatina de la alta burguesia. Dentro de estos aspectos artísticos todavía tiene especial interés la introducción por Lema del repertorio no neorrenacentista ya, sino específicamente neoplateresco, en una fecha tan temprana como 1880, y ligado a la utilización de la figura prestigiosa de Carlos $V$ en un palacio 
por la demás carente de recuerdos de la Casa de Austria, lo cual ha de relacionarse con el famoso brindis del Retiro, de Menéndez y Pelayo, en el banquete del centenario de Calderón. En cuanto a la figura de D. Juan Crooke y Navarret, conde de Valencia de Don Juan, no nos extenderemos aquí sobre su actuación como asesor artístico de la Casa Real; baste recordar que a él se debe tanto la reorganización de la Real Armería y su Catálogo (1898), como el de los Tapices de la Corona de España (1903), y que siguiendo sus criterios se restauró también la carroza negra, llamada de Juana la Loca —en realidad francesa del siglo XVII-, que vio sellado su carácter fúnebre al ser utilizada como coche de respeto tanto en la comitiva de la reina Mercedes, como en la del traslado de los restos de Calderón.

Pasando al punto de vista de imagen de la monarquía, resulta curioso notar cómo, junto a un intento de "puesta al día" formal introduciendo el gusto del momento en los grandes conjuntos decorativos de los salones de aparato, donde por lo demás no entra el arte vivo del momento como es la pintura de Historia, esta obra consolida la escisión entre la imagen pública e imagen privada del rey, dividiendo el palacio en dos mitades, y dentro de la privada distingue las piezas de reunión de las íntimas. En contrapartida, la Restauración hace asomar su carácter reaccionario al crear, en paralelo a esas "habitaciones privadas", un dormitorio oficial al otro extremo del Palacio, rasgo obsoleto que parece querer marcar una vuelta, aunque sea en circunstancias ocasionales, al ceremonial del Antiguo Régimen. Tan extemporáneo rasgo no llegará a tener consecuencias, y no creo que sóló por la muerte del rey apenas acabados los trabajos'.

\footnotetext{
' Este es el resumen de una memoria realizada para el Departamento de Arquitectura y Jardines del Patrimonio Nacional. La obra básica sobre el Palacio Real Nuevo, la de F. J. DE LA PLAZA SANTIAGO, no trata los aspectos decorativos del interior, ni siquiera la organización del espacio interno, a la que me referí en "Saqueti y los salones del Palacio Real, (Reales Sitios, 1988). No está estudiada la decoración decimonóna de los palacios reales españoles, y muy poco la de los de la aristocracia madrileña. A este respecto cabe destacar, aparte de su obra sobre Arquitectura y arquitectos madrileños del siglo XIX, el libro de Pedro Navascues Palacio "Un palacio romántico, Madrid 1846-1858, (Ed. El Viso, Madrid 1983) y los de Virginia Tovar Martin. Historia artistica del palacio de la Cámara de Comercio e Industria de Madrid (1987) y El Palacio Parcent, sede del Ministerio de Justicia (1986) publicaciones de los mismos organismos. Lema fue nombrado arquitecto mayor de palacio y Sitios Reales por Real Decreto de 27 de agosto de 1857. El 24 de octubre de 1968 solicita al Consejo de Administración los bienes que constituyeron el Patrimonio de la Corona que le confirme su empleo: lo hacen el 1 de marzo de 1869. Le cesan el 3 de junio de 1870 , nombrando a Santiago Angulo en su lugar. Vuelve a su cargo el 2 de enero de 1875, ocupándolo hasta su muerte ocurrida el 31 de septiembre de 1891.
} 
Como es lógico tratándose de una campaña decorativa unitaria, el resultado ofrecía al visitante una secuencia de salas coherente: tras subir la escalera principal y atravesar el Salón de Alabarderos, se encontraba al fondo del eje, recortada contra la ventana del Salón de Columnas que cae al patio del zaguanete, la estatua de Carlos $V$-copia encargada en 1878 a Barbedienne de la famosa de Leoni-, máxima referencia prestigiosa de la restaurada monarquía. A partir de aquí el Palacio quedaba dividido en dos mitades por el eje Norte-Sur: en la oriental, tras haber recorrido los salones oficiales que dan a la fachada principal, quedaban los espacios para la vida privada, más allá de la Cámara; en esta parte se crean los nuevos salones de billar y de fumar; en la mitad occidental los salones del antiguo cuarto de Carlos III quedaron adscritos a funciones indeterminadas de recepción que encontraban su marco preciso al final de esta secuencia en el comedor de gala. En los ángulos septentrionales del Palacio quedaban las habitaciones privadas de otros miembros de la Familia Real como las infantas doña Isabel y doña Eulalia y, luego, la Reina Madre. Tal ordenación ha llegado hasta nuestros días salvo la modificación o desaparición de algunos elementos sobre todo en la zona privada, como los salores de billar o de fumar.

Convendrá que sigamos en la exposición no el itinerario de los salones sino el proceso de su configuración, individualizándolos. Las obras comenzaron en virtud de una orden de Alfonso XII comunicada al Inspector General de los Reales Palacios en 16 de agosto de 1879, mandando "disponer los tres salones que en la fachada de Occidente del mismo comprenden el llamado de Isabel la Católica y sus inmediatos a derecha e izquierda para que puedan servir a los efectos de un solo salón, a cuyo fin deberán sustituirse los muros o paredes transversales de carga que hoy los dividen del modo más conveniente, y como consecuencia de esta reforma, decorar el nuevo salón que ha de resultar, en lo concerniente a los muros, con tapices; pues la bóvedas han de quedar independientes como hoy se hallan. Construir en el centro del salón de Columnas el pedestal en que ha de colocarse la estatua en bronce del Emperador Carlos V con arreglo al proyecto aprobado por S.M. ..."

De la ejecución del pedestal para la estatua del Emperador no tenemos más noticias, pero se conservan la planta, el alzado y una perspectiva del grupo, así como una sección del Salón de Columnas mostrando la estatua al fondo. Los diseños corresponden a lo ejecutado, tal como hoy se ve. Los bajorrelieves del pedestal son neoplaterescos, como los de la habitación junto al comedor de gala que comentaremos luego. Para la ventana que ilumina la estatua por detrás se encargó a la casa Veglisson, Dotres y Cia. de Paris, en abril de 1882, un gran cristal 


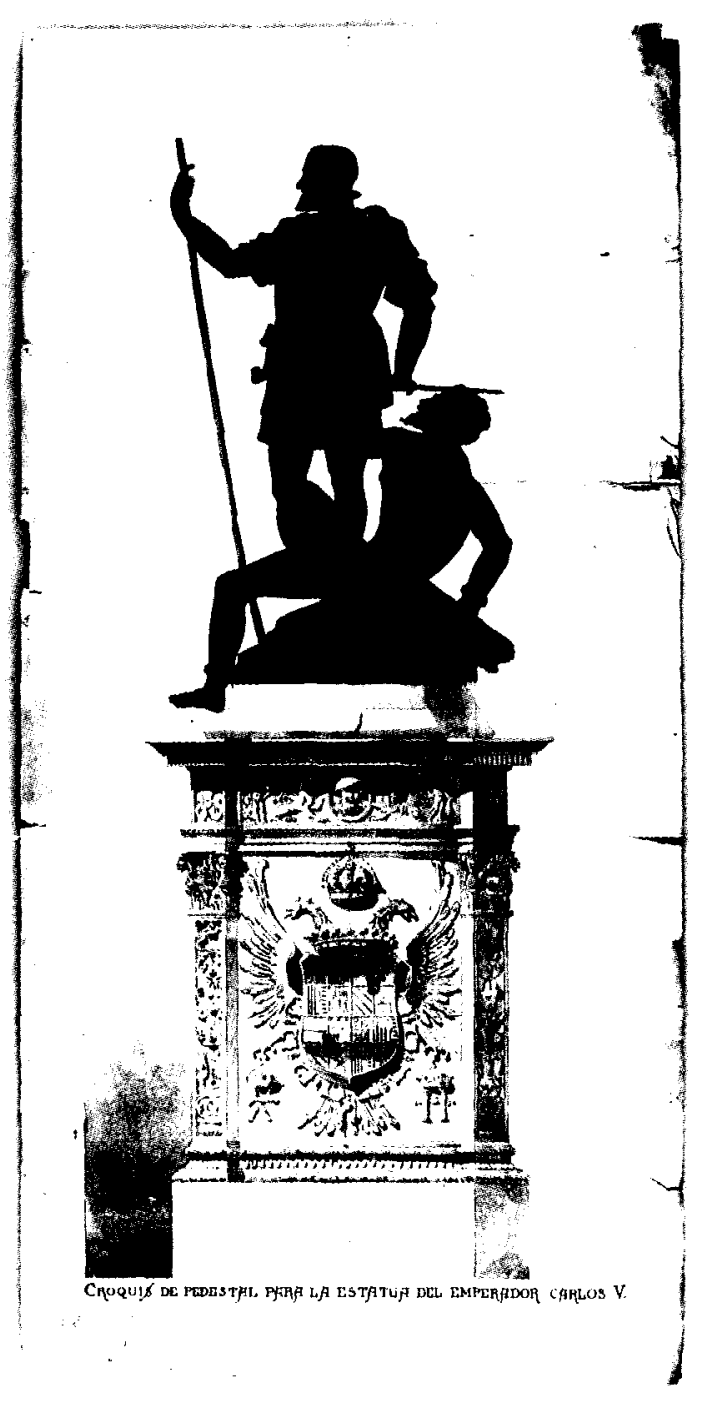

"Croquis de pedestal para la estatua del Emperador carlos $V$ " en $\in$ Salón de Columnas. 
grabado con un grupo de niños, corona y bordura; es decir, una especie de repostero vítreo ${ }^{2}$.

\section{EL SALÓN PARA BAILES Y COMIDAS DE GALA}

Este salón supuso la transformación más importante, resultando del derribo de los muros que separaban los tres salones principales del cuarto de la reina esposa de Carlos III. El estado previo se refleja en la planta y alzados levantados por el arquitecto, mostrando la distribución de las puertas y chimeneas. Su proyecto está plasmado en dos secciones, una a línea y otra coloreada. Muy influido por el neobarroco francés del Segundo Imperio en su prepertorio decorativo e incluso en los materiales -de Paris vinieron las grandes lámparas de bronce y los capiteles de las columnas, y los mármoles de Bagnères en Francia-, resulta de indudable brillantez por la ingeniosa solución espacial forzada por los condicionantes estructurales pero que aumenta a amplitud ilusoria del salón ${ }^{3}$. Lema apeó los muros transversales mediante arcos rebajados, dejando intactas las bóvedas de la cornisa arriba; las columnas y arcos marmóreos funcionan como bambalinas de escenografía. Además se levantó el pavimento de mármol de las tres salas que fue colocado, con las modificaciones exigidas por su nuevo emplazamiento, en el comedor de diario y en la Saleta y Cámara de la Infanta Isabel; se colocó un parquet de maderas finas que lo unificaba con los tres salones adyacentes con luces a la galería del patio, y los detalles de la decoración se dispusieron de acuerdo con la variante "B" del proyecto. De bronce habían de ser los ocho capiteles para las columnas y ocho enjutas para los arcos, diez sobrepuertas y siete sobrebalcones de estilo Luis XVI, 124 florones grandes y 378 chicos para los arcos, y 560 metros de moldura. También de bronce serian las quince arañas y los diez candelabros de pared comprados en París. Desde el principio se pensó en decorar los paramentos de este salón con tapices, que en la primera variante del proyecto Lema pensó hacer, aparentemente, nuevos, y que definitivamente serian de la colección real como ya aparecen en sus secciones.

2 Diseños para el pedestal de la estatua de Carlos $V$ en el Salón de Columnas: A.G.P. 3943, 4587. La planta en A.D.A. La sección, AG.D. 2221.

${ }^{3}$ Quien no llegó a ocuparlo, habitándolo durante aquel reinado Isabel de Farnesio y luego la Infanta $\mathrm{M}^{\mathrm{a}}$ Josefa. 

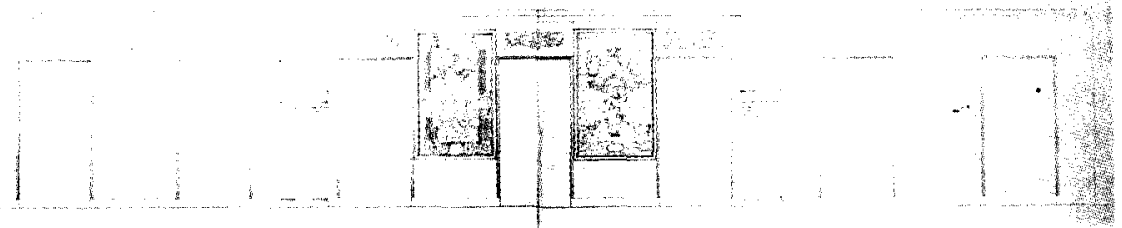

Sección del Comedor de Gala, lado de los balcones, con tapices de las series definitivamente colocadas.

La gran alfombra que habia de cubrir el entarimado se encargó a la Real Fábrica de tapices en Septiembre de 1879.

Las obras del comedor empezaron en Octubre de 1879 a la vez que las de los salones contiguos y los de billar y fumar. El jefe del oficio de la tapiceria, Tomás Green, fue enviado a París con el fin de adquirir todo lo necesario según se había expuesto en el informe previo, para que viendo las existencias de los almacenes parisinos se ajustase en sus compras más a la función y utilidad que en Madrid iban a tener tales objetos que al posible precio. En esta autorización, sin embargo, no se incluyen instrucciones relativas a compras para las piezas de billar $y$ fumar.

El 30 de noviembre de 1879, Antonio Jorge recibia el pago por la limpieza y compostura de ventanas y vidrieras para siete huecos de balcones y ocho huecos de puertas en el nuevo comedor y cuatro pedestales de madera de pino que se pintaron imitando mármol que debieron formar parte de un "efimero decorativo" preparatorio realizado por Busato y Bonardi. Estos escenógrafos cobraron el 15 de diciembre de 1879 el trabajo hecho en el comedor consistente en la pintura de las paredes en lienzo imitando mármoles, sus dos arcos y bastidores correspondientes y ocho columnas, con sus capiteles y basas. Esto ha de interpretarse como un montaje provisional con el fin de hacerse idea del efecto que la decoración había de hacer, y no sorprende que los autores de semejante "escenografía" fuesen los autores habituales de los decorados para las óperas montadas en el Teatro Real por aquellos años.

La decoración definitiva de mármol y bronce debió avanzar entre 1880 y 1884; hasta abril de 1882 no encarga Lema a Paris los ocho 
capiteles de bronce de las columnas, que sin embargo parecen haber sido realizado finalmente en mármol blanco y no recibirian su guarnición de hojas dobles hasta 1884. En cuanto a los tapices, la elección de la serie de Pomona por consejo del conde de Valencia de Don Juan marca la preferencia por las piezas del siglo XVI y el criterio ecléctico según el cual se encuadraban en un marco arquitectónico cuyas fuentes de inspiración se encontraban en el XVII y XVIII europeos. El presupuesto para añadir, retupir y colocar estos nueve tapices fue presentado el 16 de febrero de 1880 , concluyéndose el trabajo el 30 de junio de 1882 . En febrero de 1880 se disponía el arreglo de los salones inmediatos, como luego veremos. En abril se habían adquirido varios metros de telas necesarios para las cortinas del salón y se precisaba la compra de trescientos metros más para los pabellones de éstas y el forrado de los divanes. Green había conseguido de Dumet una rebaja de consideración en el precio de la tela anterior $y$, aprovechando la ganancia, se convino la adquisición de gro para las 140 sillas del comedor a principios de 1881, las cuales irian tapizándose paulatinamente a partir de abril de 1884 .

Ya en octubre de 1880 Girón presentaba la cuenta por restaurar los techos del comedor. En el de la Entrega de Granada se rascó el zócalo, se borró y quitó el color del fondo de los adornos, que se untaron de medios tintes como se hacia en los casetones, los floreros y los adornos de los ángulos y centros. También se barnizaron y doraron los baquetones y molduras de los casetones, el calado de hojas de las entrecalles, laureles, jarrones del centro y adornos del ángulo y centro. Del mismo modo se procedió en el techo de Isabel la Católica. No consta restauración propiamente de pintura.

La labor de los tapices de Pomona ya se había concluido el 30 de junio de 1882. Dos años más tarde, el 16 de junio de 1884, ya se estaba concluyendo el trabajo de tapicería pues toda la obra menos el forrado de las 140 sillas estaba hecha y la tela para las mismas estaba ya en Madrid, tan sólo a falta de adquirir el agremán y las motas.

A finales de 1888 existían en Palacio las tapicerías necesarias para las catorce cortinas de los balcones, con tres paños cada una; para las doce cortinas de las puertas fronteras a los balcones, con dos paños cada una; para las ocho correspondientes a las puertas de los extremos, con dos paños cada una, y la cenefa tejida de seda para las cortinas de los balcones, y se necesitaba adquirir aún la tela para el fondo de seda color crema de los 17 huecos. Por otra parte, hasta 1885 no quedó acabado el parquet. 


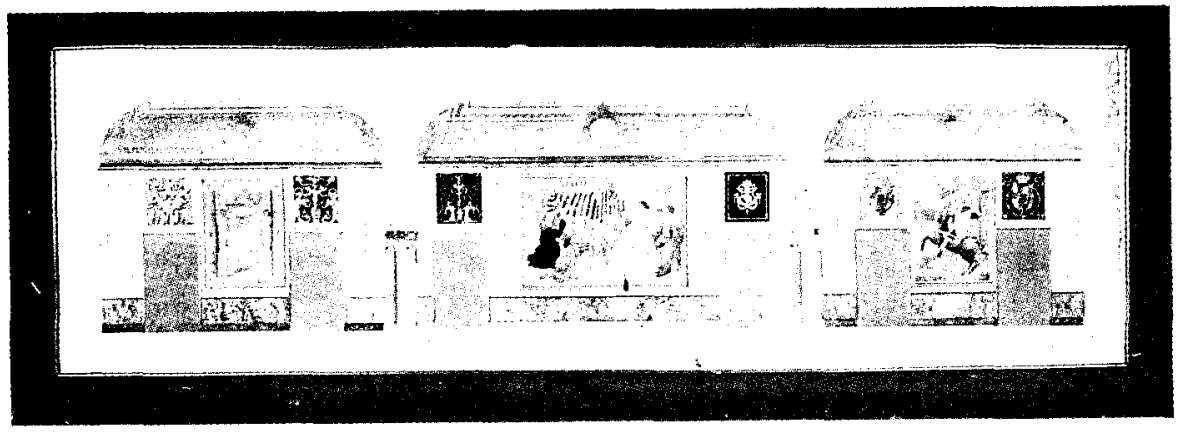

Sección del Comedor de Gala (costado interior) con variantes respecto a la decoración realizada.

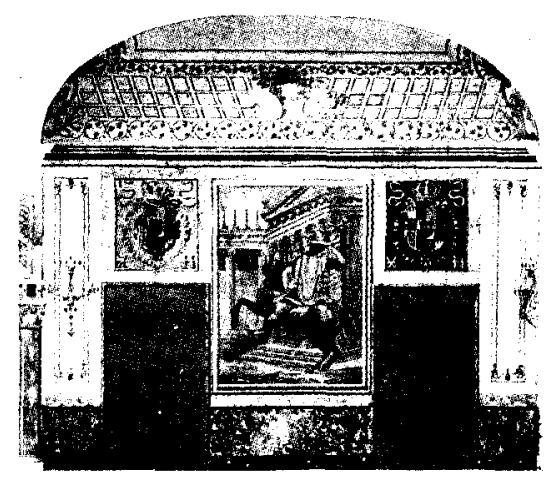

Detalle de la anterior, con la decoración tal como se realizó.

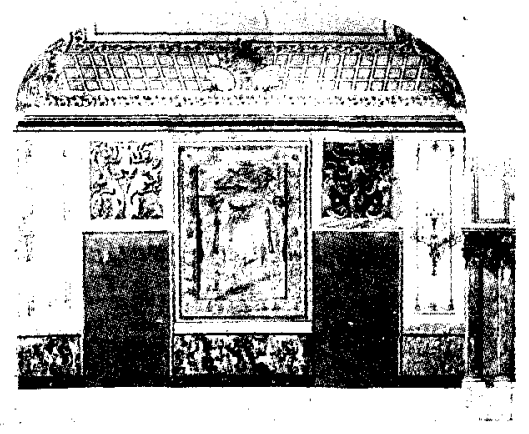

Detalle de la anterior, con la decoración no realizada. 
El aspecto que más tiempo tardó en solucionarse fue la compra en París de las arañas de Bronce. En noviembre de 1885 parece que colgaban en el comedor unas cuatro arañas, parte de un juego de seis comprado en 1849 y que antes habían iluminado el Salón de Columnas. Lema decidió prescindir de estas lámparas $y$, adquiriendo una más de cada clase idénticas a las antiguas a los mismos fabricantes, Renon, obtener un total de ocho, cuatro grandes de 66 luces y cuatro pequeñas de 24, y destinarlas todas al Salón de Columnas, donde aún están hoy. Para el Comedor de Gala se emplearon al parecer quince arañas que habían sido adquiridas también en 1849, y cuyos cristales hubieron de ser repuestos prácticamente en su totalidad; además se encargaron a otra casa parisina (Lacarpière frères) apliques para las paredes. De esta firma hay en el Archivo numerosos diseños de arañas de bronce, que responderán posiblemente a ideas de encargo no llevadas a cabo ${ }^{4}$.

\section{LOS SALONES ADYACENTES AL COMEDOR}

Tabiques, suelos y escaleras de madera formaban siete habitaciones en el lugar de las tres estancias que Sacchetti dispuso entre las piezas que ahora habian de comunicar limpiamente el comedor y la galería del patio. Lema los unificó con el comedor mediante un pavimento de madera parecido y rasgó hasta el suelo las ventanas que les daban luz, haciéndoles una guarnición de piedra de Colmenar para guardar la unidad estética de la galería donde se abrian, además de estas siete puertas vidrieras, las de la pieza de billar y otras hasta un total de veinte, con cerramientos de caoba.

De estos tres salones el central fue decorado con elementos escultóricos (bajorrelieves de talla en madera y escayola) de estilo neoplateresco. El conjunto habia de incluir una gran chimenea en nogal que finalmente fue esculpida en piedra blanca, pero en el mismo estilo; los frisos, pilastras, basas y embocaduras de nogal para ocho puertas hechas con columnas abalaustradas y molduras. De escayola se harian los capiteles de pilastra, el entablamento y los adornos del techo, y de este mismo material se hicieron los modelos para que el tallista ejecutara las citadas embocaduras. Los fondos de la ornamentación plateresca habian

${ }^{4} 7,11,12,13,14,15,21,32,36,46,48,57,53,64,65,66,67$. Las secciones del comedor se encuentran en A.D.A., los diseños de las lámparas en A.G.P. 50 a 59. 
de ir dorados, y los motivos encima pintados en blanco; los techos de los tres salones pintados, y sus paredes con colgaduras. Las jambas estrechas de los huecos que de estos salones se abren a la galeria y al salón se revistieron de mármol. Las obras de estas tres salones comenzaron por orden de 17 de febrero de 1880. Tanto la carpintería de caoba de las puertas vidrieras como la decoración tallada fueron obra del ebanista Manuel Genné, quien realizó las veinte pilastras talladas con sus basas y capiteles, sus pedestales y el friso entre ellos y los coronamientos de los huecos de paso, con sus molduras, resaltos y esculturas, según sus cuentas que coinciden plenamente con la ornamentación tal como ha llegado hasta nosotros y con los diseños conservados. Sin embargo no llegó a dorarse el fondo de la talla para que ésta resaltase, sino que todo quedó en blanco e incluso, junto a una puerta, se dejó una prueba de cómo hubiera quedado el conjunto barnizado y con la talla dorada. Esta interrupción se explica por la muerte de Alfonso XII, pues la última cuenta de Genné es de septiembre de 1885. En los dos salones contiguos el mismo Genné hizo los frisos de madera con tableros de mármol y la moldura de guarnecer y los rastreles para sujetar las colgaduras, que eran los elementos más notables en el tratamiento de ambas piezas, que para decir verdad son hoy las más insignificantes de Palacio como corresponde a su destino de office ${ }^{5}$.

\section{LA RESTAURACIÓN DE LA CÁMARA DE GASPARINI}

Al mismo tiempo que se ordenaba rehabilitar esos tres salones, el 19 de febrero de 1880, se aprobó el proyecto para la restauración de la cámara de Gasparini y el arreglo de las habitaciones entre ésta y el Salón del Trono, por un lado, y el nuevo comedor, por otro; en un primer momento realmente sólo se hablaba de abrir las segundas puertas de comunicación entre Gasparini y el comedor, eliminando el oratorio y el retrete de Carlos III y «dejando un paso o galería corrida por detrás de la sala de china y su inmediata", y reformar y arreglar los otros salones. Un mes después, el 18 de marzo, especificaba que «los trabajos de decorado están reducidos a la limpieza de techos y dorados, levantar las

${ }^{5}$ La obra de estas habitaciones está incluida en el mismo presupuesto núm. 1. Las cuentas de Genné, núm. 58, 59,60,61 y 62. El diseño de grutescos de una pilastra en A.D.A., núm. 6. 
sedas que tienen la mayor parte de las habitaciones, sustituyéndolas por otras existentes en tapicería, y algunas alteraciones en el mobiliario para ponerlo en armonía con el estilo dominante en el decorado de cada habitación, siendo de estos trabajos el de mayor importancia, el de la limpieza y restauración de las magníficas telas que revisten la cámara de Gasparini». Esta restauración tiene una evidente importancia no sólo por la de la pieza que fue su objeto sino por tratarse de la primera vez en la que la colgadura es tratada como objeto artístico y no artesanal y sometida a un tratamiento "científico", con el conde de Valencia de Don Juan como asesor. El responsable de la limpieza fue el tintorero de la Real Casa, Ledesma.

Para esta obra no parecía prudente dar presupuesto, y efectivamente así era pues al empezar en mayo la limpieza de las telas por las dieciséis cortinas, se estimó que no bastaba hacer tal cosa sino pasar el bordado a seda nueva "porque el transcurso del tiempo ha deteriorado la tela hasta el punto de abrirse en el momento en que se trata de ponerla en el bastidor para limpiarla". Para ello se hubo de comprar en París raso de color "blanco sucio" y se emprendió el paso a ella del bordado de las cortinas, mientras se procedia a la limpieza de la colgadura y a la restauración de los muebles. La seda de la pared estaba lógicamente, menos gastada que la de las cortinas y por tanto sólo precisaba una limpieza, ya muy avanzada por Ledesma en septiembre de 1880 y de la que presentó cuenta definitiva en marzo del año siguiente. En octubre cobraba Antonio Jorge la restauración de los marcos de maderas finas y bronces que guarnecian los espejos; muy dañados debian estar y faltos de muchas piezas, según su cuenta; antes estudió el que se hallaba en mejor estado, limpiando sus maderas y estudiando la colocación de todas sus hojas de adorno, e hizo un modelo "para el nuevo copete y el adorno para la división de las dos lunas". Por tanto esa división horizontal no debe ser original sino del momento que estudiamos. Además se fabricó un sillón nuevo -carisimo: 3.090 pesetas - copiando los antiguos, puesto que en el oficio de tapicería existían el asiento y respaldo bordados de uno que no llegó a hacerse y de esta manera sirvieron; es interesante notar la intervención de J. S. de Lema en este encargo.

Esta restauración consolidó hasta nuestros días el aspecto del salón de Gasparini, con la colgadura limpia y los muebles reparados y sin las cortinas, pues la restauración de éstas resultaba tan costosa que nunca se terminó, llevándose a cabo solamente la de un "pastel» o paño de coronamiento y de un par de cortinas; para hacer una sola tardaron seis bordadoras casi dos años, y para las quince restantes se calculaba un tiempo de diecisiete años y medio, y casi setenta mil pesetas. Aparte de 
estas razones objetivas, se arguyó «que el decorado del salón de Gasparini y la riqueza de las jambas de sus balcones y puertas no hace... absolutamente preciso el cortinaje ${ }^{6}$. Las escayolas del techo fueron restauradas por Francisco Poncini.

\section{LAS SALAS ENTRE LA DE GASPARINI Y EL COMEDOR}

La consecuencia más importante de la remodelación de estas habitaciones fue la supresión en 1880 del oratorio de Carlos III, que se abria a la Cámara de Gasparini frente a unos balcones, ocupando la parte más interior de lo que hoy se Ilama "tranvía de Carlos III". El marmolista Manuel Fernández fue el responsable de "desarmar todo el revestido de mármoles de las paredes del oratorio de Carlos III y bajar dichos mármoles al depósito del Campo del Moro". Allí se conservan hoy día -además de las jambas marmóreas de las puertas de los salones que estaban donde ahora el comedor de gala - la guarnición de un arco y los soportes de una mesa de altar, en mármol verde, que juzgo deben ser los de este oratorio. También desapareció el retrete de Carlos III que estaba tras la pieza "de coronas" hoy llamada sala amarilla. El resultado de estas dos supresiones fue hacer una circulación de poca importancia paralela a la principal, lo cual desde nuestro punto de vista no justifica la desaparición del oratorio ${ }^{7}$.

En el salón de Carlos III se puso tela nueva siguiendo el diseño de la existente, encargando a tal efecto 550 metros de gro color azul y 200 color crema en enero de 1881. La actual "sala amarilla" vio sus telas limpiadas, también por Ledesma ${ }^{8}$.

\section{LOS SALONES ENTRE EL DE GASPARINI Y EL DEL TRONO}

Los salones entre el de Gasparini y el del Trono, es decir la Saleta y la Antecámara de Carlos III, apenas sufrieron otra modificación que la

${ }^{6}$ Documentos 15, 18, 23, 26, 30, 33, 40, 43, 44, 45, 49, 50, 51, 56.

7 Documento 25. Sobre este oratorio, ver mi artículo "Las decoraciones fijas en los palacios reales de Madrid y El Pardo bajo Carlos III", en las IV Jornadas de Arte del Instituo Diego Velázquez del C.S.I.C., El Arte en tiempo de Carlos III, Madrid, 1988.

${ }^{8}$ A.G.P. Obras XIX legajo 38 , minuta, número 82 a 89. 
sustitución de sus telas y arreglos puntuales. En la Antecámara se limpió y restauró el techo, dorado de nuevos varias partes que habían perdido el oro, y se arregló la moldura (197 varas de longitud) que guarnece las sedas.

También en la Saleta se reparó la moldura (230) varas y se compusieron y doraron los cuatro marcos grandes de los espejos. Para las paredes se adquirieron en octubre 1880 del fabricante barcelonés Malvehy, 179 metros de lampás blanco, carmesí y amarillo ${ }^{9}$.

Por último, los tres gabinetes del despacho de Carlos III, inmediatos a la Cámara de Gasparini y con balcones al Parque de Palacio, vieron también renovada su decoración textil. El mobiliario del cuarto de D. Francisco de Asís aquí instalado se envió al guardamuebles en febrero de 1880, y comenzó la habitación de estas tres piezas que al parecer se destinaba a cuarto oficial del rey, pues al encargar a la Fábrica de Tapices las alfombras en octubre de 1881 se destacaba que estas habitaciones "son hoy, en cuanto al decorado de principal importancia por el objeto a que se destinan...". Las sedas adquiridas en París para vestir los muros de estas habitaciones fueron satén azul marino, satén carmesí, satén crema y lampás azul; además se adquirió bastante mobiliario de estilo Luis XVI -un armario de luna, un costurero, dos sillas "de lira" $y$ varios juegos de sillas también de estilo Luis XVI- que hace pensar en la instalación en estas habitaciones de un cuarto oficial de SS.MM. compuesto por tocador, despacho y alcoba según la factura de las alfombras. La muerte de Alfonso XII impidió seguramente la consolidación de esa imagen "oficial» de la Cámara de Gasparini recuperando en cierto modo la tradición de Carlos III; todas las guías de Palacio desde 1931 ignoran el destino que se pensó dar en 1880 y se les llama sencillamente habitaciones del rey Francisco ${ }^{10}$.

\section{LAS HABITACIONES PRIVADAS}

Pero las verdaderas habitaciones privadas de los monarcas eran, desde la época de Carlos IV, las que dan a la calle de Bailén. En estas salas hubo simples cambios de telas y mobiliario, pero también dos de-

9 Documentos 27 y 29. Minuta citada en la nota anterior, número 66 .

${ }^{10}$ Documentos $41,42,43,44,45$ y 47 . 
coraciones coherentes diseñadas por el arquitecto mayor que trataron de recuperar como piezas importantes dos espacios de los "trascuartos" que dan a la galeria del patio. Nos referimos a las piezas de fumar y de billar, que fueron concebidas al mismo tiempo que el comedor de gala, aunque no van incluidas en la orden de realización de éste. El 6 de octubre de 1879 pedia permiso para efectuar los gastos precisos para la decoración de estos salones ua los que no se refiere la autorización otorgada por R.O. en 16 de agosto último para llevar a efecto las obras acordadas en el salón de Isabel la Católica». Por tanto el encargo a J. S. de Lema hubo de ser formulado verbalmente por el rey a la vez que el del comedor.

\section{LA PIEZA DE BILLAR}

Esta sala era uno de los gabinetes de la reina María Luisa, en cuya época colgaban aquí, según Ponz, algunos de los cuadros más clásicos de la colección de Palacio. El techo, pintado hacia 1769 por Mariano Salvador Maella, representa a Juno y Eolo, y ha estado oculto e ignorado durante un siglo, pues la decoración diseñada por J. S. de Lema consistía en un empanelado de madera, inspirado en ejemplos ingleses y en la derivación racionalista que Viollet-Le-Duc hizo de motivos góticos. La pared estaba cubierta de madera en los tres cuartos de su altura, sobresaliendo por encima los marcos de las puertas, y la bóveda quedó oculta por un artesonado plano también de madera. Se conservan bastantes diseños de Lema para esta sala, fundamentalmente para el artesonado y los írisos decorativos con hojas de hiedra, así como los alzados de la mesa y las banquetas, y el diseño del parquet. En realidad, solo el empanelado o "boiserie" constituye la decoración; realizado todo en nogal por el ebanista Antonio Girón, comprende un friso de tableros y armadura, una faja de yedras esculpidas; una cornisa con dentellones sobrepuestos y media caña coronando el friso, cuatro cornisas en las guarmalletas de las ventanas, las puertas y ventanas con la misma decoración que el friso, y todos los tableros de la parte alta del empanelado, con filetes dorados y remates blancos y negros. Girau también hizo la mesa de billar adornada asimismo con hojas de yedra, las banquetas y las taqueras; todo ello estaba terminado en febrero de 1880. Las banquetas estaban tapizadas con cuero. Antonio Jorge acabó en septiembre un mueble también de madera de nogal y siguiendo, como en toda la decoración, los diseños de Lema; armó la mesa de billar, completó las 


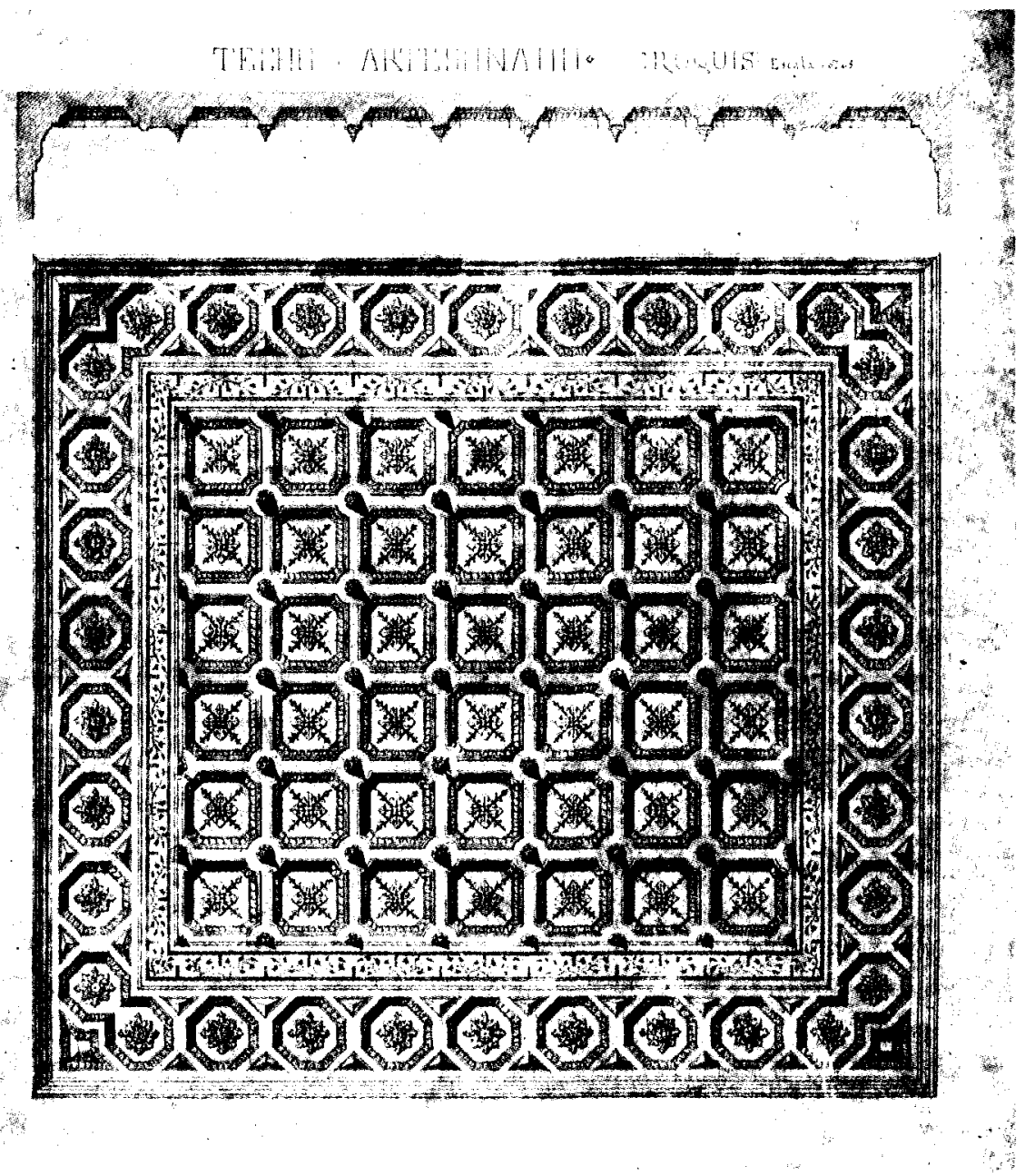

Techo artesonado del salón de billar. El realizado (que en realidad es rectángular) ofrece variantes; sobre él existe una bóveda de Maella, Juno mandado a Eolo que suelte los vientos contra Eneas. 
molduras de la decoración e hizo "cuatro bastidores de pino armados con sus cuñas para colocar tapices con sus marcos moldados y sobrepuestos de pino para pintarlos a imitación del roble", de tamaños distintos y no grandes. Nicolás de la Torre hizo seis sillas de nogal, y uuna alfombra fina de nudo dibujo turno". El conjunto estaba por tanto acabado en 1881, salvo el par de puertas vidrieras de caoba abiertas a la galería que Manuel Genné no hizo hasta $1884^{11}$. El salón de billar permaneció sin transformaciones hasta la época de Franco, cuando al montarse los "nuevos museos" de Palacio bajo la dirección del marqués de Lozoya y de Angel Oliveras se instaló en estas salas el de tapices, cubriéndose las paredes con sargas grisáceas ocultando totalmente el empanelado de madera. Este montaje que deshecho en 1987-1988, y al variar entonces la instalación eléctrica por encima del techo artesonado de madera se cayó en la cuenta de la existencia del techo pintado por Maella en perfecto estado de conservación. Esta sala presenta por tanto ahora una opción difícil entre la vuelta a su estado dieciochesco o alfonsino. Cabría la posibilidad de desmontar la boiserie y rehacerla en una habitación exactamente del mismo tamaño en un palacio caracterizado por la decoración decimonónica y precisamente marcado por una estancia de Alfonso XII, como el palacio de Riofrío.

\section{LA PIEZA DE FUMAR}

Separada del anterior salón por la «pieza de escayola» (que habia sido el dormitorio de la reina María Luisa), estaba el trascuarto de esta misma habitación que se decoró en estilo japonés como sala de fumar, siguiendo las mismas instrucciones y pasos que la pieza de billar y siempre según los diseños de José Segundo de Lema. Se conservan una perspectiva y los alzados de las paredes y embrasures de los huecos, así como dos variantes para el diseño del parquet, incorporando los divanes o no. A fines de 1879 ya estaba hecha en las paredes la obra de

1 Documentos $17,22,24,28,31,34,41,47,52,54,55,68$. Se conservan los planos de la bóveda, el artesonado y el alzado de la mesa en A.G.P., planos 5518, 4201 y 4174. Relacionados con esta sala se encuentran en A.D.A. diseños para el motivo goticista con hojas de hiedra en el friso, los perfiles de las patas de las banquetas, varios croquis de techo artesonado que no corresponden plenamente con lo realizado, uno por tener forma de bóveda y otro por tener planta cuadrada - aunque quizá se trate de uná simplificación voluntaria- y el diseño del parquet (números $2,3,8,9,13,18$ ). 


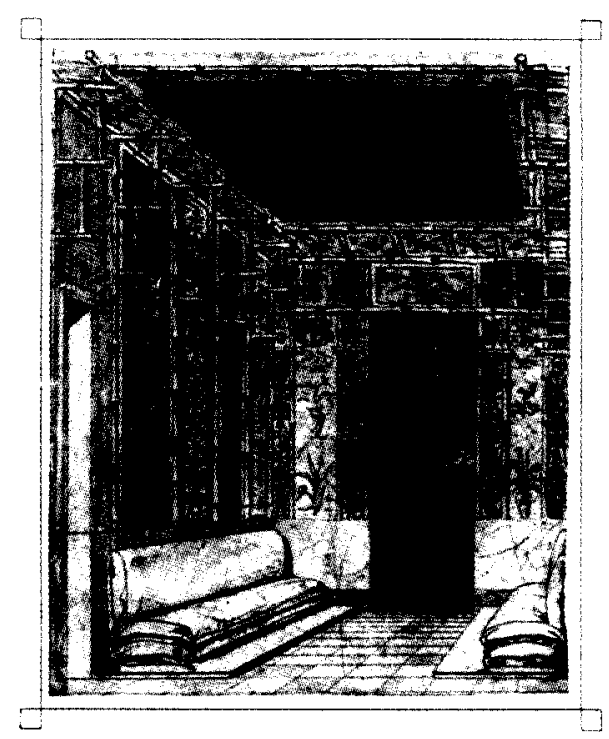

Perspectiva de la sala "japonesa" de fumar (desaparecida).

carpintería -239 metros de rastrel, cercos- que habia de soportar las placas de cerámica con decoración "japonesa" - "chambre chinoise" la llamaban las facturas de Francia--, así como el arreglo de los dos huecos a la galería, y al pasillo, y el pavimento de maderas finas de nogal, roble, plátano y tintada de negro, trabajos todos realizados por Antonio Jorge, y supervisados directamente por Lema. Las plaquetas cerámicas (plaques faience, peinture en émail), que constituían el ornamento de toda la superficie de las paredes, fueron encargadas por el arquitecto a una fábrica francesa especializada - Revetement ceramiques unis et decoratifs de la $\mathrm{H}$. Boulanger et cie à Choisy-le-Roi- a través del concesionario Bruneu, y se montaron entre 1880 , cuando se liquidó la decimonona y última factura de Bruneau, vinieron numeradas conforme a los diseños y estaban sujetas al enrastrelado de madera mediante 366 piezas metálicas servidas por Victor Esteban. La pieza debió acabarse a fines de 1880, pues la cuenta del ebanista Manuel Genné concierne a los últimos toques: el sentado de los rastreles - con forma de $T$ y de escuadra- en el techo, la de algunos rastreles en los muros y los de los huecos; la colocación de las placas en paredes y techo, diez de los diez bastidores para las pequeñas y los cinco grandes para las telas bordadas chinescas compradas a Dumet en diciembre de 1879, con fondos blanco, 


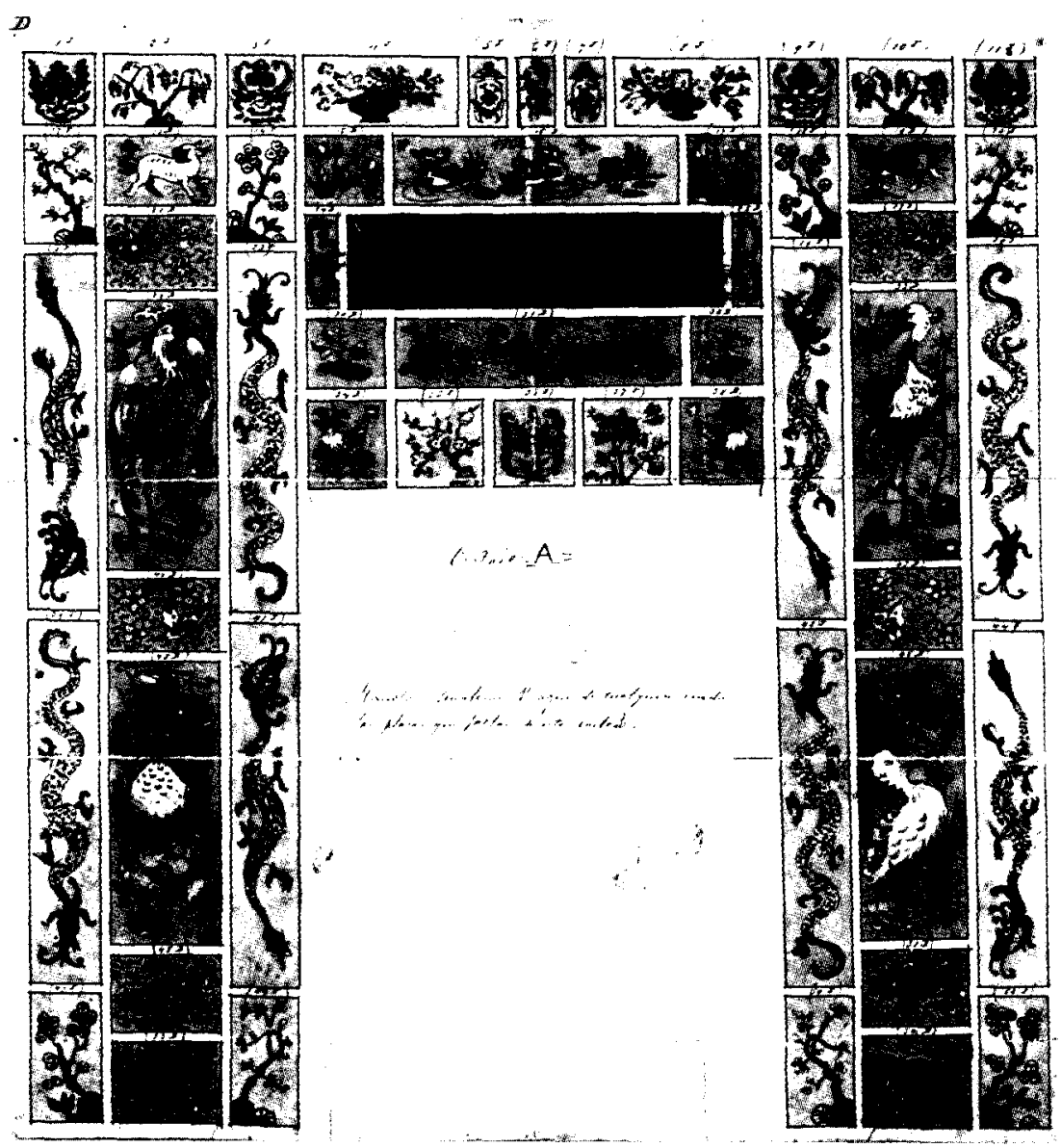

Alzado de la pared oeste de la misma sala, detallando las placas de porcelana.

azul y pajizo, y el acoplado y atornillado del bambú en el techo, la fachada y los alfeizares; doce tablas, pintadas imitando sustentar el techo y las que soportaban porcelana servian seguramente para colocar piezas de china. La alfombra no se entregó, como la del salón de billar, hasta junio de $1882^{12}$. Esta sala fue dañada por un obús que en la última guerra atravesó la carpintería de la ventana y estalló dentro; por consi-

${ }^{12}$ Documentos $7,10,20,28,35$ 
guiente fue preciso desmontar la decoración, de la que solo subsiste la puerta de salida al pasillo y la parte de la carpintería de la ventana a la galería.

\section{LAS HABITACIONES PRIVADAS}

Todos estos trabajos habían estado precedidos de otros en las habitaciones privadas de los monarcas como lógica consecuencia del matrimonio de Alfonso XII con María Cristina de Habsburgo. La Alcoba Real -que era la misma al menos desde la época de Isabel II y lo seguirá siendo con Alfonso XIII - fue objeto de una completa restauración en sus telas y mobiliario. En mayo de 1878 se había entregado a Antonio Jorge el diseño del parquet que ya estaba listo para ser colocado cuando al año siguiente el ebanista Antonio Girón restauraba toda la cama, un sofá, cuatro sillones y cuatro sillas, los marcos de dos espejos, las galerías de las cortinas y las molduras de guarnecer, y varios marcos antiguos. Las telas para esta habitación fueron encargadas a París; las bordadas para la cama a Fourdinois, y a Creuse las cortinas y pasamanerías, todo en estilo Luis XVI de acuerdo con el estilo de la cama. La colgadura de las paredes era de lamás azul comprado a Dumet. Se conservan los diseños para el parquet de esta habitación, asi como el de la alcoba del rey, luego despacho de Alfonso XIII, y el de la "pieza de estudio», en el ángulo de la calle Bailén ${ }^{13}$.

Las vecinas habitaciones auxiliares sufrieron también reformas. El baño y retrete de la reina fueron divididos mediante una cancela de pino en forma de escuadra ${ }^{14}$.

Pero, en general, parece que el aspecto "alfonsino" de las habitaciones privadas del ala de Bailén se deben más bien a lo realizado por Amadeo de Saboya, que decoró completamente su despacho, pieza de vestir y alcoba, y arregló su antedespacho, el despacho de la reina, la pieza del niño o de los médicos y la Corbella así como muchos salones

${ }^{13}$ Documentos $5,8,9,10$. Las sedas bordadas para la cama constaban de la cifra, sobre azul cielo, y "trois panneaux sur velous de soie grenat pour le petit dossier du lit Louis XV/". Los diseños para el parquet, en A.D.A. La cordonería y pasamanería era también de gusto Luis XVI. La alcoba y demás habitaciones de la reina fueron objeto de nuevas intervenciones decorativas tras su viudez, en 1886. Cfr. leg. 23 de Obras.

${ }^{14}$ Documento 7. Para la pieza de baño se conservan en A.D.A. varios diseños del pavimento de mármoles, ninguno de los dos correspondientes al realizado; igualmente está el diseño del parquet del tocador (números $5,25,30,34$ y 43 ). 
fuera de ese ala ${ }^{15}$. La época de Alfonso XIII dió lugar también a importantes transformaciones en el ala de Bailén, con nuevos retoques decorativos en la alcoba y baño, pero sobre todo con el cierre de la escalera, que desde entonces sólo llega al primer entresuelo, y la formación en su lugar de la alcoba del rey. Creo que también de ese reinado debe datar el remontaje en el despacho de la reina de las boiseries procedentes de los despachos de maderas finas de Carlos $11{ }^{16}$.

En las salas del lado digamos no oficial del palacio, las que caen a la calle de Bailén pero están fuera del ala de las habitaciones privadas, la intervención alfonsina es importante, como hemos visto a propósito de los salones de billar y de fumar, ambos con luces a la galeria del patio. En la crujia exterior se crea un ambiente historicista, el salón de armas, y se "restaura" uno histórico, el Salón de Espejos. Realmente lo que se trataba en este último era cuidar la armonía de su mobiliario con la decoración fija, utilizando algunos existentes en el guardamuebles y adquiriendo muebles en Madrid y en París, concretamente 24 sillas doradas de estilo Luis XVI compradas en 1880 a Giesendorf ${ }^{17}$. También se sustituyó el suelo existente por parquet al igual que en el dormitorio de Carlos IV llamado "salón de tapices». En cuanto al salón llamado de armas carezco de datos sobre su arreglo, pero evidentemente ha de ponerse en conexión con los criterios artísticos del Conde de Valencia de Don Juan, quien en marzo de 1880 marchó a Zaragoza a comprar unos tapices para la Real Casa. La forma del friso y chimenea bien puede ser de Lema, y se asemeja al que aparece en un diseño para una chimenea con reloj incorporado en la guarnición, que no corresponde a lo realizado. Desde luego parece suyo el diseño del parquet, y la chimenea ejecutada, que es pseudorrenacentista. Los tallados sillones historicistas han de ser puestos en relación con parecido mobiliario encargado a varios artistas hacia 1880. Por ejemplo, en 1879 Antonio Girón separaba seis sillones y seis sillas de palosanto con patas salomónicas, y doce sillones y seis

15 A.G.P., Reinados, Amadeo. Ca 39/20. Cuenta de la obra de ebanisteria hecha en las habitaciones de S.M., 1872 (despacho particular, alcoba, pieza de vestir y entresuelo de S.M.). 37/9, Obras del Real Palacio, 1872. 35/56, 12 de mayo de 1872, cuenta de la obra de ebanisteria, escultura, pintado y dorado en las habitaciones reales particulares, 1872 (la cuenta no está). 35/27, informe sobre cuenta de obras en el Real Palacio. 30/3, arreglo de la antecámara. 30/8, del despacho de la reina. 30/7, del antedespacho del rey. 30/6, de la Saleta. 30/4, de la Cámara. 30/1, del comedor de diario. 30/2, del salón carmesi. 30/9, de la pieza del niño o de los médicos. 30/10, de la Corbella, 30/11, del salón de Espejos. 38/ 17, arreglo del Campo del Moro. De la Corbella se conserva un diseño para el parquet en A.D.A., número 27.

${ }^{16}$ Acerca de estas obras de Alfonso XIII, A.G.P., leg. 5208 bis

17 Minuta, 73, 76, 105. Documento 37. El diseño del parquet en A.D.A. 22 y 24. 
sillas de nogal; Antonio Jorge hizo "una silla a la romana, copia de una antigua del emperador Carlos $V$, su madera de nogal talladas y una mesa de nogal con uforma del siglo XVI, tallada sus pies y chambrana» ${ }^{18}$.

Otras intervenciones de esta época tuvieron lugar en la planta baja de Palacio, destinada al alojamiento de príncipes extranjeros. Busato y Bonardi pintaron cinco techos, uno en el techo de la sala de tapices de Goya, otro de estilo pompeyano, y tres con celaje, pájaros y flores ${ }^{19}$. De Busato y Bonardi deben ser los autores de los techos semejantes de esta misma época en el piso principal, como el de la sala de fumar, los "tranvías" de la Cámara y de Carlos III, etc.

Las obras de decoración de Palacio quedaron interrumpidas con la muerte de Alfonso XII, el 17 de noviembre de 1885: se suspendieron las obras en curso y se planteó la cuestión de por qué partida habian de pagarse las facturas pendientes, que finalmente cargaron sobre el abintestato del monarca. Prácticamente todo estaba acabado pero quedaron sin hacer para siempre remates como la pintura del "salón central»o bien tardaron en colocarse, como es el caso de las lámparas en el comedor de gala. Por otra parte, muerto el rey y con una reina viuda regente en nombre del hijo póstumo, poco sentido habian de tener piezas como el "cuarto oficial» del rey en Gasparini, o el salón de fiestas y comedor, y menos aún los salones de billar y de fumar, en una corte enlutada y sin monarca adulto.

Por tanto, durante los años siguientes las obras fueron básicamente de reparación ${ }^{20}$, pues a la campaña decorativa que hemos estudiado

${ }^{18}$ Documentos 3, 7. Los tapices comprados en Zaragoza costaron 13.000 pesetas. El diseño para chimenea relacionado con este salón y el del parquet, en A.D.A., números 7 y 29.

19 Documento 2.

${ }^{20}$ En 1884 se decora la Saleta y Antecámara de la infanta Isabel (Obras, leg. 25) y en 1886 las habitaciones de su hermana la infanta Eulalia (id., 29). Otros gastos por reparaciones y limpieza de las habitaciones reales en 1886 (id., 29) y sobre todo en 1896, cuando Enrique Repullés Segarra, como arquitecto mayor interino, rinde cuentas por obras de decoración en Palacio (A.G.P., Obras XIX, leg. 63) que fundamentalmente son las siguientes:

- Alfombra de la Real Fábrica para la escalera del Príncipe.

- Nuevo salón de S.M. el Rey: lo mismo, y colgadura de lampás rojo, de Tassinari et Chatel.

- Gabinete azul y pieza de música de S.M. la reina: tapiceria y muebles.

- Composturas en varias alfombras del principal.

- Pieza de recibir de la infanta Isabel: tapiceria (colgaduras de damasco carmesí).

- Alcoba y otras habitaciones de S.M. la reina: cortinas y dos armarios Luis XVI para la alcoba.

El 21 de mayo de 1890 había dado orden la reina regente para que se reemplazasen 
tomaron forma todas las intenciones alfonsinas para poner al Palacio Real en consonancia con la imagen victoriana o Segundo Imperio de las residencias reales europeas, y con el reflejo de las mismas en los interiores de la alta burguesia y la aristocracia: el "salón de tapices" con falsos muebles Enrique IV o la serre -imitada de la parisina de la princesa Matilde- que Clarín nos describe en el palacio del marqués de Vegallana son prueba de ese parentesco; no hay que olvidar que también el Palacio de Madrid iba a contar con su serre, un enorme pabellón de hierro y cristal sobre el ala de la Botica de la plaza de la Armería, que no llegó a realizarse.

Como decíamos al principio, nuestro tema es quizá más interesante desde el punto de vista histórico-sociológico o de imagen de la monarquía que desde el puramente artístico. La etiqueta de la Corte del Antiguo Régimen -borgoñona de origen, con carta de naturaleza en España, determinante en la francesa de Luis XIV que a su vez refuerza ese aspecto de representación hacia un público restringido- se basaba en que la existencia cotidiana del Monarca, hasta en sus aspectos más intimos, estaba regida por un ceremonial y mostrada a la Corte como en un escenario cuyo soporte físico eran, dentro del palacio, salas con atribuciones concretas, distinguidas por su función y por quién podia entrar en cada una, nadie podía sentarse a comer en la mesa del rey (recuérdese el cuadro de Paret); su despertar, su toilette, el vestirse; hasta el parto de la reina (bien que sólo ante los primerísimos dignatarios) eran públicos. Precisamente fue María Cristina de Habsburgo la primera en negarse a dar a luz ante otros que no fuesen los médicos, y aunque muy amante de la etiqueta, y apoyada en ello por su cuñada la infanta Isabel - sin embargo de haberse educado en el ceremonial ya mixto de su madre-, esta señora tenía al fin y al cabo dos hijas y un hijo rey que criar, y en este sentido las habitaciones privadas no podian ser otra cosa que el centro de la vida de Palacio.

Las revoluciones burguesas hacen que todo cambie, y el reflejo llega también a la vida de los monarcas como representantes de la idea del Estado. Como una irónica vuelta a la teoría medieval de los dos cuerpos del rey -el natural y el público- su figura quedará escindida entre la representación y la vida personal. A través de las vacilaciones a este respecto durante el reinado de Isabel II -cuando van imponiéndose las

con mármoles los pavimentos de baldosa ordinaria de barro cocido que existian en las habitaciones del piso bajo, destinadas al alojamiento de príncipes extranjeros, desde la Puerta del Principe al ángulo de la fachada norte. Los mármoles blancos para estos pavimentos se trajeron de Barcelona. 
exigencias de los tiempos y de la intimidad - se llega a plantear la necesidad de algo impensable cincuenta años antes: un gran comedor de gala donde el rey comerá en una mesa con 140 personas, y cuya contrapartida son, por supuesto, las habitaciones privadas.

\section{DOCUMENTOS}

1. 16-8-1979; José Segundo de Lema, 1879: “Presupuesto aproximado de las obras de reforma y ornamentación mandadas ejecutar en los salones de las crujías occidentales del Real Palacio, en los destinados a Saleta y Cámara de S.A. la Infanta Isabel y en las galerías del piso principal central de la fachada oriente".

2. 26-8-1978: Busato y Bonardi: cuenta de pintura de techos en la planta baja de palacio (techo de la sala de tapices de Goya, otro estilo pompeyano y otros tres con celajes, pájaros y flores.

3. 31-8-1879: Antonio Girón: cuenta por muebles y marcos.

4. 6-10-1879 Oficios de Mariano Orueta al Intendente General de la R. C. y P. para que Tomás Green, jefe del decorado, vaya a Paris para adquirir los efectos necesarios para la decoración de los salones indicados en la orden del 16-8- $\left(n .^{\circ} 1\right)$ y además la pieza de billar y salón de fumar.

5. 31-10-1879 Antonio Girón: factura por restauración de muebles y marcos.

6. 31-10-1879 Antonio Girón: factura por restauración de muebles y marcos.

7. 30-11-1879 Antonio Jorge: factura por diferentes obras de ebanistería para el retrete y baño de la reina, pieza de fumar, comedor de gala, silla y mesa al estilo del siglo XVI.

8. 30-11-1879 Antonio Girón: factura por restauración de muebles en la alcoba de S.S.M.M. y marcos.

9. 9-12-1879 Oficio acusando los pagos hechos a Dumet y Lucien.

10. 12-12-1879. Facturas de Creuse, Fourdinois, Boyer y Dumet por telas, al parecer todas para la alcoba de S.S.M.M. 
11. 15-12-1879 Busato y Bonardi: factura por la obra de pintura imitando mármol en el comedor de gala.

12. 16-12-1879 Oficio comunicando las letras pagadas en París por diferentes efectos de decoración.

13. 6-2-1880 Factura de Proudhomme por barras, anillas etc. para cortinas.

14. 16-2-1880 Sabino Stuyck. Presupuesto del retupido, recosido, añadidos y colocación de los tapices de la serie "Pomona".

15. 19-2-1880 Real Orden para rehabilitar los tres salones entre el comedor de gala y la galería: abrir las puertas de comunicación entre Gasparini y el comedor; y reformar y arreglar los salones intermedios entre estos dos salones y los restantes hasta el salón del trono.

16. 25-2-1880 Factura de Proudhomme por efectos de tapiceria.

17. 28-2-1880 Antonio Girón: cuenta de la obra hecha en la pieza de billar.

18. 18-3-1880 Especificaciones sobre la R.O. de 19-2 (n. $\left.{ }^{\circ} 15\right)$.

19. 31-3-1880 Factura de Dumet por lampás crema.

20. 8-4-1880 Facturas de Adrien Bruneau por cerámica esmaltada (en faience) para la sala china (de fumar). Son diecinueve la liquidación final firmada por José Segundo de Lema el 7-121880 asciende a mil quinientos francos.

21. 12-4-1880 Oficio sobre compra de más tela para los divanes y pabellones de cortinas del comedor de gala.

22. 30-4-1880 Antonio Girón: cuenta de la obra en la pieza de billar (últimos toques).

23. 10-5-1880 Oficio sobre la restauración de las cortinas de la cámara de Gasparini.

24. 31-5-1880 Antonio Jorge: factura de la obra que se ha hecho en la sala de billar.

25. 15-6-1880 Manuel Fernández: cuenta del desmontaje del revestimiento de mármol del oratorio de Carlos III.

26. 14-6-1880 Oficio sobre el encargo a Francisco Ledesma de la restauración de las telas de Gasparini, por indicación del Conde de Valencia de Don Juan. 
27. 30-6-1880 Antonio Girón: factura de la obra de restauración en el techo de la antecámara y de molduras de guarnecer para la misma antecámara y saleta así como los divanes y marcos para esta habitación.

28. 31-7-1880 Victor Esteban: factura de piezas de cerrajería para las piezas de fumar $y$ del billar.

29. 31-8-1880 Antonio Girón: factura de cuatro marcos grandes para la Saleta.

30. 2-9-1880 Oficio sobre los 17 paños de cortinas y asientos de Gasparini ya restaurados por Fco. Esteban Ledesma.

31. 30-9-1880 Antonio Jorge: factura de un mueble para la sala de billar.

32. 31-10-1880 Antonio Girón: factura por la reparación de los techos de la entrega de Granada y de Isabel la Católica, ambas en el Comedor de Gala.

33. 31-10-1880 Antonio Jorge: factura por la reparación de seis marcos de maderas finas de la Cámara de Gasparini.

34. 4-12-1880 Nicolás de la Torre: factura por seis sillas para el salón de billar.

35. 3-12-1880 Manuel Genné: cuenta de la obra de carpintería en la pieza de fumar.

36. 12-1-1881 Oficio con la factura de Dumet por el gro para tapizar las sillas del comedor.

37. 12-1-1881 Oficio con la factura de Giesendorf por 24 sillas para el salón de espejos.

38. 18-1-1881 Oficio sobre compra a Dumet de más telas para la decoración de los salones entre Gasparini y el comedor.

39. 17-2-1881 Oficio sobre la restauración de las tapicerías de la pieza inmediata al nuevo comedor.

40. 31-3-1881 Francisco Esteban Ledesma: factura por la restauración de las cortinas de Gasparini.

41. 21-10-1881 Oficio sobre la fabricación de cinco alfombras para las tres salas inmediatas a Gasparini, la de billar y el trascuarto de la pieza de escayola. 
42. 26-10-1881 Oficio sobre pago a Dumet por las telas para el despacho, contiguo a Gasparini.

43. 16-12-1881 Relación de las telas y muebles que es necesario adquirir en París para la decoración del salón de Gasparini y habitaciones contiguas.

44. 17-12-1881 Oficio sobre la tramitación del gasto para lo anterior (entre 10 y 12.500 pts.).

45. 15-3-1882 Oficio y facturas de Dumet, Giesendorf, Creuse, Gibert, Lucien y Antoine para la decoración de la sala de Gasparini y contiguas, por un total de 19.865 pts.

46. 14-4-1882 J. S. de Lema al intendente general, sobre el encargo a París de los ocho capiteles de bronce para las columnas del comedor, por un importe de 15.130 francos.

47. 30-6-1882 Gabino Stuyck: factura de las cinco alfombras encargadas el 22-10-1881 (n. ${ }^{\circ} 41$ ).

48. 30-6-1882 Gabino Stuyck: cuenta del coste del retupido, recosido y añadidos a los tapices de la serie de Pomona (ver $\mathrm{n}$. 14).

49. 20-11-1882 Nicolas de la Torre por un sillón nuevo de maderas finas para la cámara de Gasparini.

50. Noviembre 1882. J. Esteban Lozano: por bronces para el salón de billar y para el sillón nuevo de la cámara de Gasparini.

51. 3-1-1883 J. S. de Lema al inspector general, sobre el sillón nuevo para Gasparini.

52. 31-10-1883 Antonio Girón: factura por obras de ebanistería en la pieza de billar.

53. 30-11-1883 Antonio Girón: cuenta por molduras para la saleta de la infanta Isabel.

54. 4-1-1884 Manuel Genné: cuenta de dos huecos de puertas vidrieras de caoba.

55. 10-1-1884 J. S. de Lema: Relación acompañando la cuenta anterior.

56. 6-10-84 Oficio sobre suspender la restauración de las cortinas de la Cámara de Gasparini. 
59. 3-10-1884 Manuel Genné: factura por la obra de carpinteria en los siete huecos de puertas vidrieras que dan a la Galería.

60. 5-12-1884 Manuel Genné cuenta del friso y pilastras del salón central y del friso para los salones laterales.

61. 4-3-85 Manuel Genné: factura por la obra de carpintería en los salones entre el comedor y la galería rastreles, molduras, cuatro pares de puertas de caoba.

62. 4-9-1985 Manuel Genné: cuenta de carpintería y talla salón central.

63. 20-10-1885 José Esteban Lozano: factura por elementos para guarnecer los ocho capiteles del comedor y colocarlos.

64. 17-11-1885 Oficios sobre la adquisición de arañas de bronce para el salón de columnas y comedor.

65. 7-12-1885 Manuel Genné: cuenta del entarimado del comedor.

66. 18-6-1887 Factura de Renon (París) por una gran lámpara de 66 luces y otra de 24 , en bronce dorado.

67. 24-12-1888 Presupuesto del coste que tendría hacer todas las colgaduras de los 17 huecos del comedor.

68. S.F. «Cuenta de la obra de carpintería, ebanisteria y talla... de una sala para billar». 